\title{
THE IMPACT OF TEACHER TALK ON STUDENT ENGAGEMENT DURING AN INTEGRATED STEM UNIT
}

\author{
Valarie Bogan, Graduate Student, Purdue University
}

\begin{abstract}
This study used a hermeneutic phenomenological approach to investigate the effect of teacher talk on the engagement of students in target groups during an integrated STEM unit. Each student in the target groups responded to the teacher talk in a unique way. The results of this study do not fully support the results of prior research because the engagement of only one of the eight target students was affected by the autonomy supportive talk of the teacher during the unit.
\end{abstract}

\section{Introduction}

One of the reasons teachers are encouraged to use integrated science and engineering units is that these learning devices are supposed to increase students' engagement with the content and increase their motivation to pursue a career in a STEM field (Bybee, 2013). Many researchers believe that teachers can increase a student's motivation through their words and behaviors (Stroet et al., 2013). This study investigates if a teacher's talk during an integrated engineering unit affects student engagement. This study was framed under Self Determination Theory (Ryan \& Deci, 2000).

\section{Methods and Results}

The participants for this study were two $8^{\text {th }}$ grade science teachers (Mr. Hale and Mr. Evans pseudonyms) and four students for each teacher. The data was collected with a video camera placed at the back of each room and an iPad on the target group's table. Researchers transcribed the whole class videos verbatim. These transcripts were coded based on the characteristics of autonomy supportive teaching obtained from the literature. A rating scale was used to determine the engagement of each target student every day of the unit (Reeve et al., 2004).

In general, Mr. Hale's talk did not support student autonomy and therefore engagement. The engagement level of one of Mr. Hale's students was directly affected by his autonomy supportive talk. Mr. Evans' motivational talk did support student autonomy. None of his students' engagement was linked to his motivational talk.

\section{Discussion}

The results of this study do not fully support the results of prior literature. All the students were affected by parts of the teachers' autonomy supportive talk at specific points in the unit, but only one had engagement that consistently responded to the teacher's talk. One type of autonomy supportive talk, invitations to verbally participate in the unit, caused most students to become engaged in the lesson. Therefore, a teacher should monitor student responses to different types of motivational talk and use those which are most effective at engaging their students.

\section{References}

Bybee, R. (2013). Case for STEM education: Challenges and opportunities. National Science Teachers Association. Retrieved from ProQuest Ebook Central, https://ebookcentral.proquest.com/lib/purdue/detail.action?docID=1416112

Reeve, J. Jang, H., Carrell, D. Jeon, S., \& Barch, J. (2004). Enhancing students' engagement by increasing teachers' autonomy support. Motivation and Emotion, 28(2), 147-169.

Ryan, R. M., \& Deci, E. L. (2000). Self-determination theory and the facilitation of intrinsic motivation, social development, and well-being. American Psychologist, 55(6), 68-78.

Stroet, K., Opdenakker, M., \& Minnaert, A. (2013) Effects of need supportive teaching on early adolescents' motivation and engagement: A review of the literature. Educational Research Review, 9, 65-87. 